\title{
Diaspora space
}

\section{This Is Not Cricket!}

Listen son, you cyan mek your own choice. But I will never again play with those people. Let me tell you why. The round-robin tournament begin too early. It should come as no surprise, operating on Island Time as we do, that our game not starting on time. Most of us there by 9 a.m., but by the time we each had on our ointment, bandages, gears and whatnot, it was already 9.30. We batting first, so it not so bad that we still waiting on Otis and Sam, at 10 a.m. But they called to say they were on their way. We easily won the first game without them even batting. I think the opponents underestimated our skills. We ol' but we not frail! It was only 20 overs. We finished and on to game two of the tournament by 11.30 .

Most of us West Indians playin' with a few Indian and Sri Lankan police officers, so I cyan't say I really shocked when there was trouble, but I had hopes for the best. I knew there were only two things the fellas needed to play well: sunshine and golden juice. You know what I'm sayin'? I had a cooler with plastic cups, ice and a Gatorade bottle full of Courvoisier. I know technically we were playing on the team that represented Law and Order, but a few sips of the good stuff is all we needed to get through the afternoon. And it was hot! You cyan't expec' all we dry out in the sun. Once Layton had a sufficient amount of what he called "blood thinners," he said he could easily bat his age. Yeah, he 48 but that's his reputation. He nearly did it too! We poured from the Gatorade bottle and sipped out of Tim Horton's mugs. No one had to know what we were up to.

Since the first innings of the second game, the smell of curry flooded the air so we knew lunch comin' up. At 2 p.m. we were finished. Victorious again. But by the time we made it to the food marquee, there was nothing left but the dregs of butter chicken and a few scant grains of basmati rice. The red oils pooled at the bottom of the chafing dish mocking us with the memory of the departed tandoori chicken.

Let me ask you this: was it merely a coincidence that the organisers forgot to save some food for the only black team in the tournament? Our opponents got. Everyone else got. What we got? Nothin! Charles, always known for speaking his mind, call out, "They probably figured we wouldn't eat that shit anyway!" They probably figured he was rude as he finished his third beer and threw the empty water bottle at the fence, near, but not in the garbage can. Charles went with the police team captain, Prasham, to Popeye's Louisiana Kitchen and returned with 
spicy fried chicken, biscuits and french fries. That fried chicken was delicious, see?. I'll take it over that tandoori nonsense any day.

Then get this. After lunch, they say the umpire slated to work our game busy on another field. That game was still at least one hour away from being finished, so the organisers tried to replace him with an umpire who was the opposing team captain's brother! They t'ink all we stupid? That's a conflict of interest! We got into it with the umpire and words was getting heated when he finally refused to work our match, calling us "a bunch of drunks." Can you believe it? Us? Drunks? Not a t'ing go so.

Marshall call out, "Indians organise and you see which games on television, who gets the good fiel' and the umpires!" And Erol screaming, "They forget all we lunch and all we umpire?! I don' need to fucking sit around and watch this jackass steal outs for the other team. This is not cricket!" You should a seen that scrawny ass hole organiser wit' he squeaky voice. "Listen, I will not stand for this. I cannot bring more food. The original umpire is busy on the main field! I can not bring the television crews to film this match. They are already set up over there. For your information, I'm not in charge of the drinking laws of the province either!" He repeated several times that there was to be "no drinking in the park." I had no patience for this little man wit' his beady eyes and his stupid rules. A little brandy ever hurt anyone? Half of the team grab up our gears and walk off the field. I don't know if they continued without us. I don't care. Like I said, you can play for who you want. Me? I done wit' dose people. I stop playin' wit' dem.

Afro-Caribbean-Canadians resist racism from whites whose homes line the cricket fields on which they play. But this is not the full extent of race relations in Toronto cricket. There are other transnational histories and crucibles of diasporic trajectories 'where Europe is not at 'the center' - which retain a critical bearing on understanding contemporary diasporic formations and their inter-relationships." Thus, it is necessary to deploy "diaspora space," which is a concept introduced by Avtar Brah (1996) to explore the lateral connections between diasporas - the ways "in which different historical and contemporary elements are understood, not in tandem, but in their dia-synchronic relationality" (p. 190). Diasporas can be understood based on their unities, disjunctures and their relationships to other groups. We must take a range of diasporas into account to understand the Afro-Caribbean diaspora.

The narrative "This Is Not Cricket," shared above, captures the bellicose and racist ways the Afro-Caribbean Mavericks referred to and interacted with Indians, Bangladeshis, Pakistanis and Sri Lankans (hereafter, South Asians) in Toronto's cricket spaces. It is the result of observations made at a local tournament combined with stories told to me by one elderly black BarbadianCanadian club member, Warlie, who sometimes played alongside his 47-yearold son in friendly Master's games. I have no interest in either endorsing or 
excusing the Mavericks racist comments. Rather, I present their discriminatory words and capture their disempowered feelings to set them against a context of historical and contemporary Indo-Afro relations in the Caribbean and its diaspora. Their description of what is "not cricket" (not fair) at the cricket grounds highlights not only challenges to the socially constructed rules of the game, but also challenges to the socially constructed boundaries around their communities. Analysis of racialised and ethnic difference, Peake and Trotz (1999, p. 5) write of Guyana, "is not simply about different people with disconnected ways of doing things but rather about unequal access to power, about the relations through which differences are produced and reified." A range of fusions and new categories are created when people from different cultures meet. However, there may also be resistance to a mestizo identity, refusal to integrate and rejection of creolised cultures, based on historical antagonisms between groups. Hannerz (1997, p. 8) reminds us there "may be a preoccupation with cultural autonomy and the defense of a cultural heritage for its own sake, yet frequently this rhetoric of culture is closely linked to power and material resources as well." This chapter outlines the ways in which language, food, music, alcohol and cricket rules are used to create boundaries around the Afro-Caribbean community that excludes not only South Asians, but also Indo-Caribbeans.

\section{Historical Indo-Afro Caribbean relations}

Brackette Williams (1991) alerts us to how individuals continue to interact with people of other ethnic groups based on meanings of earlier periods. Today's hierarchies are

constructed along paths well-trod by Europeans centuries earlier as they fashioned themselves into different races, nationalities, and nations ... if we are to provide informative accounts of [peoples] struggles ... we must take into consideration the complexities of historically constituted interpretations of the nature of social and cultural interchanges. (1991, p. 15)

The history of Indo-Afro relations in the Caribbean is not incidental to the story of the Mavericks and sport in the Black Atlantic. Interactions with people of Indian heritage is foundational to the creation of boundaries around black Caribbean identity.

This history begins in a context where East Indians arrived in the Caribbean, in significant numbers especially in Guyana and Trinidad, as indentured 
labourers to replace enslaved African labourers after the abolition of slavery in the 1830s. The social subordination of both these groups in relation to European colonisers, their subsequent battles for power within postcolonial nation building projects, Indo-Caribbean subordination at the hands of Afro-Caribbean nationalists in nearly every territory, alongside creolisation of unequal social and cultural elements in the Caribbean and the diaspora politic must be included in any examination of Afro-Caribbean people and diaspora cultures. ${ }^{1}$ In Trinidad, for example, where the descendants of enslaved Africans and indentured Indians comprise 34.2 and 35.4 per cent of the population respectively (Central Statistical Office, 2011, p. 94), calls for cultural unity belie intense economic, cultural and political competition between the two groups. Munasinghe (2001) shows a political movement to break free from neo-colonial political practices - in which government decisions were dictated by the economic interests of white and black middle-class elites - initially attempted to include lower-class Africans and Indians in solidarity; however, conflicts among ethnic groups at all class levels eventually divided the country. The black "majority" retained ownership and control of the government and economy, thereby subjugating the IndoTrinidadian population.

In Jamaica, Africans are reported to have resented Indian competition for work and wages, and feared that Hinduism and Islam would have adverse cultural influences (Shepherd cited by Mohammed, 2009: 62). In Barbados, Indians are reported to have perceived Africans as lazy, materialistic and prone to criminal activity (Beckles, 2004). Across the Caribbean, what were once black lower class cultures such as calypso, were promoted to the stature of regional symbols, thereby making the ruling group ethnically 'invisible' as a consequence of its claims to represent mainstream national culture.

In a cricket context in particular, Afro-Indo conflicts were at a peak as the predominantly black Windies team ruled the world in the 1970s and 1980s. It is well known that Indo-Trinidadians and Indo-Guyanese fans commonly supported the team playing against the Windies if there were no Indo-Caribbean players on the Windies, as was generally the case during this period. Indo-Caribbeans were significantly marginalised from elite playing opportunities and the Indian national team, depicted by the black dominant group as weak and feminised in contrast to strong, fast, masculine black players, constitutes an important way the Mavericks understand their own embodied black sporting masculinities. Important for this study is also the increasing migration of South Asians to Toronto including areas such as Peel Region, with more wealth and political power than black groups who have been there for decades. The more recent decline of the Windies and 
improvement of South Asian teams in international cricket also shape the ways in which these older black men resist encroachment on what they believe are "their" cricket.

As Carrington (2007, p. 52, emphasis in original) has noted about identity, drawing on the work of James Clifford and Howard Winant, "identity needs to be understood as a strategic intervention by marginalised communities for cultural, political, and economic recognition." That recognition may be sought from other black groups, dominant white groups, or the South Asian diasporas. Therefore, any study of contemporary Afro-Caribbean culture and politics must account for the historical ways in which Afro-Indo relations are loaded with the previous politics of slavery, indentured service and postcolonial nation-building projects in the Caribbean as well as contemporary issues of Windies decline and increasing South Asian migration to Toronto. This analysis extends the concept of the Black Atlantic beyond an inward-facing focus on shared transnational cultures and racial terror to an outward facing focus on relational boundary making and the real and symbolic violence enacted by blacks.

\section{Space invaders}

The Mavericks have vituperative interactions with South Asians who are portrayed as invaders because they use cricket spaces to perpetuate their own cultural heritage and gender performances. We know that ethnic groups generate boundaries around themselves based on shared criteria for evaluation. Their contrast to groups with other criteria for judging values, heritage, gender and ethics allows boundaries to be delineated. Importantly, contact with other groups is necessary to clarify where the boundaries are and to structure "interaction which allows the persistence of cultural differences" (Barth, 1998, p. 16). In the diaspora context, then, conflicts among the predominantly black Mavericks and other South Asian teams and tournament organisers, as well as disagreements among differently identified MCSC members over music, language, food and alcohol consumption at the cricket ground challenge our understanding of the Afro-Caribbean-Canadian diaspora as an independent group. And, while we may be eager to explore relations with African-Americans and black British men, we must acknowledge that diasporas are complex, multi-generational, ethnically heterogeneous, constructed in relation to other diasporas and embedded in historical and local contexts.

The Mayor's Cup (which originated in 1998, sponsored by the cities of Mississauga and Toronto) was spurred by a number of South Asian municipal 
councillors and members of the Federal and Provincial Parliament from the suburban cities of Toronto: Brampton and Mississauga. These cities in Peel Region are affectionately (and by some, pejoratively) referred to as "Bramladesh" and "Mississaugistan" for their rapidly increasing South Asian populations. The organiser, Akash, claimed the "aim of the tournament is to recognise and encourage the sporting contributions of ethnic minorities in the city." Although Caribbean boys and men had been playing cricket in Toronto for nearly two decades prior to the inaugural Mayor's Cup, it was not until South Asian politicians were willing and able to organise the event, find sponsors and gain media coverage that cricket came to be recognised as an important sport for the region's ethnic minority groups. The Mayor's Cup occurs at a multi-field venue with four simultaneous games. The event opens each year with a speech by the organisers and local politicians and then Toronto Mayor David Miller, an avid cricket fan, participated in a symbolic over in 2008. The Mavericks were invited to play in the Mayor's Cup via the Toronto police team, which always has a berth in the tournament among seven other predominantly South Asian teams.

The police team has always played friendly games and was once comprised predominantly of Caribbeans, but is now run by South Asians. "I captained the police team for 10 years" Vilroy, a 68-year-old black Barbadian-Canadian, claimed:

It used to be 95\% West Indian ... But as guys retired, not too many West Indians came up to replace them. They rely on immigration from cricketing nations to fill the spots. That's why you see so many Asians on the team now. In the 1970s and 1980s there was more immigration [from the Caribbean] and more black players. (Vilroy)

Many of the Caribbean police officers who started working for the police force in the 1970s, including Vilroy, have retired from it and/or from cricket. Nevertheless, a number of MCSC members still come to watch the police games and socialise with their friends and some are recruited to play when the police team's numbers are low. In 2008, four South Asian police officers joined ranks with eight Afro-Caribbeans (current and former officers and their friends) for the Mayor's Cup.

At every public park in Toronto, public drinking is prohibited. The Mayor's Cup featured no obvious sharing or selling of alcohol or food from cars in the parking lot. There was no loud music playing during the game and the atmosphere was serious and competitive, rather than the joking, festival atmosphere of typical Maverick matches. The cultural influence of the organisers was seen and heard at the tea break: aloo gobi (potatoes and cauliflower) and naan (flat bread) were served along with tandoori chicken and rice, and the classical music 
of Pandit Hariprasad Chaurasia was played over the loud speakers. Some of the Mavericks managed to drink in a clandestine fashion out of water bottles, coloured plastic cups and coffee mugs. Their surreptitious actions were noticed and they ended up in conflict with the tournament organisers and some of their own South Asian police officer teammates.

"You cannot drink beer here!" Akash, one of the organisers, passed by the Maverick's bench to remind them. "You see dis?" Otis, a black 47-year-old Barbadian-Canadian, indicated the clear blue skies and warm weather, as well as his frustrations with the organisers. "All dis an' me cyaan't even have one beer?! Raaaas!" Erol echoed his sentiments "Raaaas! What is the point of the weekend?" Akin to Caribbean women's kissing of their teeth, the expletive "Raaaas!" indicated frustration among many of the Caribbean men in the club.

Akash explained, "I don't make the laws, but we have to follow them" Otis promptly replied, "I ain't following no Indian nowhere," which resulted in a momentary stand-off before the Indian-Canadian police team captain, Prasham, interrupted the palpable tension and the tournament organiser walked away. As Akash left, he called out, "You are here to score runs, leave the celebrating for after!" That led to an explosion of expletives among the Mavericks: "Listen to this jackass!" "You gotta be kiddin' me!" "Fuck him an' all dese coolies" "Try an' stop me!" The Mavericks grumbled in disbelief that their fun was being curtailed. Though none of the current police officers was drinking, it was clear that outsiders were policing the "police team."

This argument must be situated within a context of Caribbean culture, which members of the Afro-Caribbean diaspora strive fervently to replicate; historical and local politics and entrepreneurial power, from which black Canadians have been effectively marginalised; and international cricket politics, in which the Mavericks are embedded as fans. Their imperative to relax on the weekends and celebrate cricket with "one beer" during, rather than after, the game, exposes the degree to which they are assimilated into the typical Canadian working week from Monday to Friday. The "point of the weekend" is to relax and turn that world upside down. The world of carnival, as many writers on the theme have stressed, is a negation or subversion of the structures, hierarchies and values that obtain in society during the rest of the year. Carnival is the world turned upside down'" (Burton, 1995, p. 95). For these Caribbean men and women, cricket spaces are carnival spaces that allow for a make-believe counter-society. If they spend their weekdays in paid and unpaid employment, ruled by the clock, stress and a (in many cases white) supervisor, MCSC members negate those norms on the weekends at cricket matches. They aim to enjoy themselves, abandon 
oppressive rules and be with people like them. They use the cricket grounds as a venue in which to relax. For them, drinking is an essential component of relaxing and performing black masculinity.

Warlie, exasperated, walked away from the field as fighting erupted among his black and Indian team members. I followed him and asked his opinion about the disagreement. At 50 years of age, he had been frustrated that the South Asians were "too aggressive and too cliquey," prompting him to leave league cricket:

Just about 20 years ago I switched to friendly games ... The reason for that is in my late stages they had (pause) there were lots of (pause) I don't want to say (pause) Indians and Pakistanis and Sri Lankan people coming ... They're very aggressive. They're a very aggressive people and they want to fight. They come to the games and change the rules. When the decisions don't go their way they want to fight the players, they want to fight the umpires, and that's when I realised that's not for me and I left and I joined the older group, my age group and I play friendly cricket.

Warlie had vowed to play cricket only with his age group and only with other Caribbean players and is comfortable in that environment at the age of 70 :

I used to play for Police, but their style of cricket don't suit me because the police team has black people, white people, Indian people, and I find dat I used to play with them. When the black guy's runnin' the show, you get a game. But then the Indian guy he takes over, and then the next thing he does he bring all his Indian friends to play ...Then you know there will be some fight like this ... I say "no thank you." I came today because [Arnold] ask me, but mark my words, today ... I stop playin' wit' dem.

Arnold, a 63-year-old black Barbadian-Canadian who continues to work for the police services, remains one of the few links between the Mavericks and the Police Club. His overt attempts to keep the peace between his two communities are increasingly futile. Warlie's frustrations demonstrate that unlike the "fights" MCSC members have among each other, where they act miserable, yell, swear and ridicule each other, but always walk away as friends, the loud exchanges with South Asians are laden with an animosity that is not resolved. MCSC members criticise South Asians for being too cliquey, competitive and argumentative. While these acts are seen as uncivilised and "not cricket," MCSC members remain comfortable with their own yelling, drinking, swearing and cliquey behaviours. In fact, these behaviours are how they define their black masculinities, which is relational to South Asian masculinities. As Brah (1996, p. 183) states: “The manner in which a group comes to be 'situated' in and through a wide variety of discourses, economic processes, state policies and 
institutional practices is critical to its future. This 'situatedness' is central to how different groups come to be relationally positioned in a given context."

From a historical point of view, Afro-Caribbeans were situated as antagonists to Indo-Caribbeans. As Caribbean planters faced the prospect of the end of indenture, any hint of solidarity between black and Indian labourers "was speedily crushed ... [and] images of the shiftless, lazy African and the industrious coolie [Indian] circulated with increasing frequency" in Trinidad (Niranjana, 2001, p. 262). Throughout the Caribbean, Indo-Caribbeans stereotype Afro-Caribbean men as having an overly strong emphasis on liming, socialising and conspicuous consumption. People with Indian heritage, in contrast, are seen as obsessed with work, highly organised and financially stingy. It is in relation to these differing stereotypes and self-descriptors of ethnic groups within a Caribbean setting that we must read interactions between the primarily black Mavericks and their South Asian teammates and tournament organisers in a diasporic setting.

In just a few decades, many South Asians have transformed their transnational migration experiences into successful businesses that sponsor the Mayor's Cup, successful careers in mainstream Canadian politics, and successful media outlets such as the Asian Television Network, which covers the tournament. Their entrée into business and politics in Toronto stands in contrast to CaribbeanCanadians, who have historically been excluded from these fields owing to economic constraints and racism (Henry, 1994). Caribbean migrants who have been playing cricket in Toronto for twice as long have significantly fewer resources at their disposal. Now that they are (nearing) retirement age, they are even less likely to mobilise resources to secure their own grounds, build clubhouses, or organise large-scale, televised tournaments. Nevertheless, retrieving and claiming space for cultural autonomy remains one means of survival within Canadian society for both of these marginalised ethic groups.

If the everyday stories we tell ourselves, individually and collectively, come to stand for who we are, it is clear that the Mavericks tell themselves they are not like South Asians. The groups' alternate definitions of sport - as a space of leisure or competition, as a place to use business contacts and political resources to build up the local profile or to relax and enjoy oneself - demonstrate that sport is always a dynamic object of struggles, with various groups vying for the capacity to impose the legitimate function of sporting activity. For the Mavericks, who choose only to play "friendly cricket," that legitimate function includes celebrating black culture through music, food and drink, whenever possible. 
The most skilled of the Mavericks play friendly games with the MCSC and continue to compete on league teams. When I inquired, "What is the biggest difference between friendly and league teams?" Riddick, a black 54-year-old Barbadian-Canadian, immediately responded, "Bus trips! A lot of Indian guys don't travel. That's their culture. The bus trips are black trips." But, I interjected, "What about [Michael]?" Michael is a 56-year-old Indo-Guyanese-Canadian who is always present on the bus trips Riddick described. In fact, Michael is one of the informal team social coordinators and often recruits people for dances, parties and bus trips. Riddick clarified: "[Michael] goes everywhere. He is the blackest black man on the team!" Riddick tried to clarify, "He likes to dance and party. Indians don't drink. They wouldn't fit in so we don't invite them." He points out two important aspects of Mavericks cricket: travelling and drinking, and labels these activities "black."

The majority of club members self-identified as black, though the full range of phenotypes and ethnicities found in the Caribbean were represented. More important than any biological or essential definition of blackness is the hegemony of black culture in the majority of the Caribbean territories (Segal, 1993), in Windies cricket (Devonish, 1995), and in the Caribbean diaspora (Joseph, 2014). ${ }^{2}$ Black is used not to refer to African heritage, or dark skin, but as a marker of Caribbeanness. Or, as Niranjana (2001, p. 261) put it: "[i]n spite of the ambiguous nature of the relationship between nation and nationalism in the West Indies, what is evident is the Afrocentric basis of the claim to being West Indian." The Caribbean diaspora is reproduced through the same hegemonic processes that promote and privilege black culture (e.g., carnival, steel pan and calypso) and identity as "authentic" across the Caribbean region, and suppress the cultural expressions of other groups (Brereton, 1979; Hintzen, 2002; Mohammed, 2009; Munasinghe, 2001). While there are of course, many "Indians," (both Indo-Caribbeans and people from the subcontinent) who drink alcohol, Riddick uses the biased idea that drinking is "black" to justify his club's exclusionary practices. Only those who embrace Afro-Caribbean culture, such as Michael, were welcomed "while the Mavericks ignore, subordinate and exclude expressions of Indo-Caribbean identity such as abstaining from alcohol, or listening to chutney-soca, Bhojpuri, or bhangra music, because they don't "fit in" on the bus trips" (Joseph, 2014, p. 680).

Cricket is an area in which the signifier "Caribbean" is internally contested in Canada. Rather than flying to Trinidad or Guyana to experience racial antagonisms, one merely needs to drive to the suburbs of Toronto. There, it is likely that 
a man like Michael will cite the Black Stalin calypso song "Tonight the black man feelin' to party/ tonight the black man feelin' to jam" in reference to himself, despite his Indian heritage. Similarly, Lawrence, who has Spanish and Portuguese ancestry and light skin once exclaimed, "All o' we black, you know. In Canada dey tek a look at me and dey don't know I black till I start talkin' ... That Negro culture is Trini. I go die black, you know." ${ }^{\prime 3}$ These claims seem to expound racial solidarity between Afro-Caribbeans and other ethnic groups when, at the same time, they conceal racial antagonisms. If Lawrence entered the Mavericks spaces and tried to assert a white Caribbean identity, or advocate for creole (as opposed to "negro") culture, his membership might be short-lived.

One man who has been an MCSC member and cricket player for nearly 30 years was born in Pakistan. He describes himself as an "adopted West Indian" and over the past three decades has learned to perform Afro-Caribbean masculinity alongside MCSC members. Another member, a 68-year-old white man, learned to play cricket in his native England and has occasionally played with the Mavericks since the early 1980s. He stated, "If you join a black club, that's what you expect," with reference to the Mavericks dancing to soca for hours after their games. He was careful to avoid asserting English ways of playing and celebrating, or vying for a leadership role in the "black club," despite his 25 -year tenure, because of his racially subordinate position.

Each of the Mavericks is "black" in relation to the white dominant group in both Canadian society and the South Asian dominant group in cricket. White- and Indo-Caribbeans, Pakistanis and English players are included in MCSC activities only insofar as they are willing to perform and adopt "black" Caribbean culture, defined as dancing, partying and drinking. One exception to this is Indo-Caribbean music with an emphasis on liming; for example, chutney-soca, a carnivalised expression of Indo-Caribbean culture, from artists such as Ravi B. and Hunter. ${ }^{4}$ Puwar's (2004) advice to pay attention to which bodies are missing or "out of place" helps to hone my focus on the ethnic groups absent from the bus, the cricket pitch, or the Mavericks social events. Because older South Asians and Indo- and Afro-Caribbeans are equally fervently passionate about cricket, we might expect more ethnic mixing within teams or between opponents. Especially as the Mavericks age and are desperate at times for local opponents of their age and calibre, it might be helpful to have an Indian or Sri Lankan team against which to play. However, language, food, age, religion, drinking and other cultural differences lead to conflicts among the groups. 


\section{Barriers of language, food and drink}

Verbal misunderstandings between Afro-Caribbean and South Asian cricketers were one of the most common reasons given to justify why the Mavericks' segregate themselves from local South Asian teams. Riddick, a black 54-yearold Barbadian-Canadian claimed that at the cricket ground "Indians speak in their own language. You know, this makes me really, really upset. I don't know why they do this. It creates a barrier. Are they saying things they don't want us to know?" He was vehement that "we are in Canada" and he communicates in English "so that should be the language on the field!" Hussein, a 66-year-old Indo-Trinidadian-Canadian, reported feeling excluded by South Asians when he attempted to join a league team in Mississauga: "The Indians tend to speak their language all the time, although they can all speak English. Don't know if that was a power thing, to 'don't let other people know what I'm talking about' you know? ... They just shut you out. And they just keep you out." Hussein's position as an Indo-Caribbean man made him acutely aware of the differences between Indians and Indo-Caribbeans and the linguistic barriers he experienced fuelled his attachment to the MCSC and a Caribbean identity: "So I just come here [to Mavericks' games] and stick with the West Indians."

Wesley's experience was similar. The black 57-year-old Jamaican-Canadian was eager to continue playing competitive league games, but saw the influx of South Asians as a problem. He considered moving to another team because of the shifting demographics in Brampton: "There are only five West Indians left and all of the other 195 club members are Pakis. There are too many and I can't understand what they're saying half the time." My discussions with Wesley and others about their use of the term "Indian" to refer to all South Asians and the derogatory name "Paki" revealed (1) an assumption on their part that I, as a racial insider, would not be offended, and (2) their feelings of anger and disempowerment in what were once "their" spaces. South Asian players increasingly use local grounds as their population in Toronto continues to grow rapidly. Between 1996 and 2001, for example, the number of people in Canada who reported a South Asian origin rose by 33 per cent (Lindsay, 2007b, p. 9), whereas over the same time frame the Caribbean population grew only 11 per cent (Lindsay, 2007a, p. 9), with the majority moving to Toronto. With this increase in population came an increase in the use of a variety of South Asian languages in cricket spaces.

The Mavericks resented the ways in which South Asians turned "their" cricket grounds into Bengali, Hindi, Tamil, or Urdu spaces when there are fewer and 
fewer places in which Caribbean people can comfortably speak in their native languages in Canada. Despite the Mavericks' admonishments that South Asians should speak "proper English," the Mavericks chose to speak in a combination of Canadian English and their native languages, fusions of the English or French of the colonisers of their respective islands and territories and the West African languages of their ancestors. When I sought him out after a game in order to conduct a formal interview, George, a 47-year-old Barbadian-Canadian, replied "me noh wan' fall dung you know! Leh we go fin' some food an' t'ing" (I don't want to faint. Let's go find something to eat). He put on a thick accent when he discussed food, which foreshadowed the delicious traditional Bajan meal he was about to eat. His predominant use of patois or speaking English with a Caribbean accent at the grounds with his peers directly contrasts with the Canadian English that he chose to speak in his daily work as a Registered Nurse and while I formally interviewed him: "Janelle, I've been here since 1986 and this is a multicultural society, I get that, but my free time is spent predominantly with black people. That's my preference and I make no apologies for that. This is my club." His ability to speak both languages fluently evinces a duality that can be framed as bi-national belonging, acculturation and double consciousness. His disdain for hearing languages other than those of his community evinces his use of cricket grounds for much more than sport.

Nakamura (2009, p. 100) explains that although shifting accents can be endearing or friendly, done to "tease" an outsider, it can also be used to exclude. While I could understand most of what they were saying, when the Mavericks were keen to say something (often private, sexist, lewd, or racist) they did not want me to hear, understand, or record in my field notes, they would pour their accents on thickly, or use terms I was unfamiliar with, to mark me as "Other" and exclude me from conversations. The Mavericks' own resistance to using "proper English" may keep South Asians away. At the same time, South Asians use their own languages to create a boundary around their communities and exclude black people from conversations. In Western societies, Caribbean languages and accents are banished to the domestic realm or "black space" (Carrington, 1998), in which Caribbean people are separated from non-speakers and feel comfortable to use their native tongue without being judged. Language is yet another way the boundaries around Afro-Caribbean-Canadians are drawn. When the linguistic boundary is challenged, an opportunity arises to reflect on what makes these black Canadians unique and what makes them feel safe in a black Caribbean homespace. 
In addition to barriers of language and accents, the ways club members use language is incomprehensible for, or unappreciated by, outsiders. AfroCaribbean men experience an inextricable link between talking and drinking, playing cricket and eating at the same time. Their talking also involves aggressive and derisive joking and making lewd or racist commentary. For them, the content of the words with which they communicate is less important than the style of their delivery (Abrahams, 1983) and cricket is a space in which talking is used to develop and express their gendered "reputation" values (Wilson, 1973). The amount of time the Mavericks spend making fun of the ways South Asian men talk indicates that particular communication modes are valued. The Mavericks perceive performances of South Asian masculinity through speech codes as incongruent with Afro-Caribbean values.

Especially as they get older, Mavericks are concerned less about sport and more about camaraderie, meaning that talking around the boundary, in a manner they feel comfortable, is increasingly important. Learie, a black 56-year-old GuyaneseCanadian, laments that times have changed and it is not only differences in language, food and jokes that keeps the Mavericks away from South Asian cricketers.

Before I left [a competitive cricket team] there was a big influx of Sri Lankans and the problem was that when they came, the whole atmosphere changed ... In the pas', we hang out as one, a whole group after each game. We either went to a pub or a bar or went to somebody's house and they'd cook up curry ... But the Sri Lankan guys started coming in and there was quite a number of them. Then they started hanging out by themselves, you know pretty much and then you know, having their own little cliques kind of t'ing, didn't want to eat wit' us and t'ing.

It is interesting to note that curried foods might have been a point of convergence for the two ethnic groups, given the predominance of the spice in their regional dishes, but Learie blames Sri Lankans for excluding the Caribbeans and their cooking. These types of conflicts over food are characteristic of the meeting, clashing and grappling Pratt (1991, p. 33) describes when different ethnic groups find themselves sharing the same space; these "contact zones" can become contentious if conflicts are not resolved.

In addition to eating their favourite, home-cooked foods as they play, or after their games, the MCSC members prioritise drinking alcohol, mainly in the form of rum, brandy, beer and wine which puts them into conflict with some of their South Asian, in particular, Muslim, counterparts, who prioritise the sanctity of sport, leaving the celebrations until afterwards, and abstaining from alcohol. During a home game scheduled for fifty overs, some club members began to complain that the game was too long. "This should be a 20-20 game!" Marshall exclaimed. Riddick 
responded "Yeah, it's a lot of overs. [I want] bang bang (he emulates the sound of the ball hitting the bat) and let's drink." He made the true intention of the gathering known: "At least the water break is a beer break." Under the auspices of cricket, drinking and its attendant socialising are the foci for many of Afro-Caribbean men (Joseph, 2011a). I arrived to many games early enough to watch the Mavericks' pre-game routines and noted that players were constantly complaining about joint and muscle soreness, but few did any warm-up routines or stretches. My attempts to suggest a fitness regimen elicited a lot of laughs: Winston, a black 59-year-old Antiguan-Canadian joked, "The only fitness these guys do before the game is the bottle! Well, you see it in the morning. That's the only fitness (motions drinking a beer). They got very strong elbows and biceps (laughs)."

At every game, before the captains tossed the coin to determine who would bat or field first, sideline drinking had already begun. "Jamaica Rum" is not a real brand name. Nevertheless one spectator, announced, "Jamaica Rum is the official sponsor of the match!" as he offered cheers to other spectators. He continued, "My sport start!" By lifting a bottle of beer to his mouth, he indicated that he is involved in a pre-game drinking competition with only one objective: keep drinking. Spectators were not the only ones involved in that "sport." Many of the cricketers enjoyed a few brandies before taking the field. Layton, a black 48-yearold Barbadian-Canadian, explained why he did not need to stretch or exercise before his matches: "You will see a lot of cars and you will see the trunks open and once the trunks are open we are having our little ritual, which is our pre-game spirits. We call it "blood thinners" which keeps the body loose." A few players performed two or three stretches and gentle throwing and catching drills before some of the games, but this did not preclude them from imbibing also. Although drinking in public is technically a breach of local laws, if it is done from a cup or plastic bottle, or a glass bottle covered with a paper bag, the Mavericks do not seem concerned. This type of behaviour is in direct conflict with the values of some South Asian and in particular Muslim cricketers, who eschewed the breaking of local laws, were more concerned with sport success than socialising and disliked being surrounded by intoxicated teammates and opponents.

\section{Fighting for power}

On the rare occasions that they played on integrated teams, the Mavericks engaged in regular arguments with their South Asian teammates over adherence to the rules of cricket. As the Mavericks became more intoxicated over 
the course of the afternoons their arguments became louder and some players' tirades attacked individual South Asian men. Their rants must be read as a combination of a stylised performance of anger congruent with Caribbean masculinity and expressions of a kernel of fury owing to feelings of dispossession and decline in physical and social power.

One afternoon late in the summer of 2009, in a game between the Mavericks and the police team (which also featured some Maverick players), a fight broke out over whether players should be called off the field once they make fifty runs so that others can bat. Prasham, the police team captain wanted to give everyone a chance to play. The Mavericks were adamant that the rules of cricket should never be changed regardless of the circumstances: "If he is out there to make 100 runs then let him have the spotlight!" "What he doing out there? Making runs! You gonna call him in, send another man out dere do the same thing? Dat make sense?!" "Every cricketer takes a chance when he comes out to the grounds that he will not bat, especially if he is late in the order. Every cricketer knows that!" "If the lead batsmen stay out dere all day I consider it like myself staying out dere. Some people here ain't see a ball! Dat don't matter! Dere are rules! You don't make it up as you go along." The Mavericks' vehemence about adherence to the rules of cricket is reflective of the era in which they grew up, their commitment to cricket traditions, and perhaps most importantly, the passion with which they protect their spaces from the intrusions of other diasporic groups. Prasham shouted to the Mavericks to "Stop that! Stop that! It's just a game so we should all have fun and get a bat." On his side were other South Asian Canadian police officers, one of whom was next in the batting order, "I don't leave my house 10 hours to go field! ... We all want a knock!" He yelled back.

Cricket has always been a space in which black Caribbean men could assert their physical and intellectual prowess, generate a welcoming community and reinforce their heritage; however, MCSC members are decreasingly able to use cricket for this purpose due to club members' moribund physical potency, declining number of active players and miniscule representation in politics and media, relative to South Asians. The strong links that MCSC members are able to generate with Caribbean communities within Toronto and other diasporic nodes, provides an "option for escape or exit, which coincidentally may dampen the immigrant's interest in political participation in general, or radical political action or systemic reform more seriously" (Rogers, 2001, p. 184). Thus, a cycle occurs where Caribbean-Canadians feel marginalised by the host, turn to the homeland or other sites for a sense of comfort and security, fail to invest in improving their status and degree of assimilation in the host land, and continue to feel marginalised. 
Ironically, the Mavericks admonish South Asian players for not speaking English, eating a restricted diet, fighting at the grounds and behaving in an uncivilised manner, criticisms that are often levelled against their own communities. They do not consider how their own behaviour is exclusive and raucous, or how they might be simultaneously alienating or subjugating Indo-Caribbean or South Asian members of their own teams who do not share their values. As Carrington (1998, p. 291) argued about cricket in the Caribbean diaspora, we must carefully qualify claims that this sport is fully emancipatory and unifies the Caribbean community. He used as an example the lack of women's teams in the club he studied, but the conflicts that arise among cricketers of Indian and African descent in a diaspora space provide another example of the disjunctures of black communities.

Afro-Caribbean-Canadian cricketers feel increasingly marginalised within Toronto's official cricketing communities, in part owing to the small numbers of second-generation or new immigrant Afro-Caribbean cricketers. Recreational and youth cricket are brimming with South Asian players, and as a result, the Mavericks efforts to protect the cultural exclusivity of "friendly" cricket are intensified. They resent the intrusion on what they consider to be their spaces by South Asian cricketers and use terms such as "invasion" and "interference." This language is reminiscent of popular Afro-Caribbean discourse of the 1970s, of an East Indian "takeover." In particular, in Trinidad and Tobago strides made by East Indian business and professional classes into sectors that were long considered Afro-Trinidadian preserves were alarming to Afro-Trinidadians (Munasinghe, 2001). The Mavericks goal is to generate a sense of home at cricket grounds. The more firmly they hold on to their nostalgic reflections on the way things were before they encountered so many South Asian cricketers, the more conflicts they end up in with South Asian teammates, opposition and tournament organisers. To avoid these conflicts, they try to limit their play to black-only teams.

Analysis of the Afro-Caribbean-Canadian Mavericks interactions with South Asian-Canadians helps to expand Paul Gilroy's narrow analysis of the Black Atlantic cultural forms as created through the racial terror of modernity (1993, p. 73). While those terrors were inaugurated by slavery, the resulting identities cannot be understood outside of the process of indentureship as well. The project of racial emancipation in the Caribbean did not occur in a world merely "split into white and black halves, and where the darker half was held back by race prejudice and legal bonds, as well as by deep ignorance and dire poverty" (DuBois, cited by Gilroy, 1993, p. 116). In fact, in the postcolonial era, black people dominated the majority of the Caribbean territories (Guyana and Trinidad are exceptions). The desire for a black homespace among cricketers 
and their supporters perpetuates a black Caribbean dominance that excludes, marginalises and denigrates Indo-Caribbean cultures as "inauthentic" representations of Caribbeanness and masculinity.

Although the Mavericks generally do not enjoy playing alongside South Asians, there are teams in Toronto that feature many positive interactions between Caribbeans and South Asians (see Razack, 2009). The main difference between these teams and the Mavericks is the age of players and the value of competition. The Mavericks are older men who have enjoyed primarily Caribbeanonly cricket since the 1970s. In Canada, young Indo-Caribbean migrants and female cricketers in particular have been exposed to mixed-ethnicity cricket throughout their competitive careers. Also, these groups are more often engaged in league play in their schools and communities where the competitive nature lends itself to recruiting the best players regardless of ethnic background (Walter et al., 1991). Because the Mavericks' objectives include (re)generation of their Afro-Caribbean cultures, communities and consciousness, they are unable and unwilling to share cricket sites with South Asian-Canadians who may be good players, but interrupt the (re)making of Afro-Caribbean homespaces.

Demanding that ethnic "Others" speak proper English and using derogatory names are racist tropes used by ethnic groups that feel their hegemony is being threatened. Drawing from John Clarke's "magical recovery of community," Fletcher (2011, para. 3.2) similarly argues that, "when one's community identity is under threat, community members may attempt to recreate, through symbolic manifestations, a sense of their traditional cultural identities as a substitution for its 'real' decline." In the case of the Yorkshire County Cricket Club, exclusionary practices, racist language and normative whiteness are couched as "tradition" but efforts "to protect their heritage by denying many ethnic minorities access to the imagined community" reveal the club's institutionalised racism (Fletcher, 2011, para 6.12), and practices of exclusion. Inter-diasporic group conflicts reflect the shifting social hierarchies and identity-making processes of migrants. Any analysis of racialised diasporas cannot be read only in relation to the dominant white group because sources of conflict and identity marking often stand in relation to other minority ethnic and diaspora groups. The examination of diaspora space, that is, lateral and horizontal interrelationships within diasporas is necessary to move beyond "racism" in our historical and ethnographic theorisations of diaspora among black and Caribbean diasporas. As Thomas and Clarke (2006, p. 14) note: "[O]ther circulations [are] equally critical in the unveiling of counter histories and the constitution of community"; for example, examining overlapping networks that connect transnational communities such 
as Caribbeans and South Asians demonstrate the importance of other axes of power such as language, religion, age and political and economic power in the making of culture and marking of identity.

Afro-Caribbean Canadians rely on liming, which involves socialising, consuming an abundance of traditional Caribbean foods, drinking alcohol, playing domino games, sharing nostalgic memories, recounting ribald jokes and playing cricket to claim not only a black Caribbean identity, but also a Canadian one. As Walcott (2003: 147) puts it, when "[w]atching cricket [in Toronto ...] bodies of colour actually and symbolically refigure Canadian space and make their presence felt beyond the confines and restrictions of immigration legislation, multicultural discourse and policies, and the local police." Making connections to other Afro-Caribbeans through sharing a sport known to be central to anticolonial efforts is one way of assuaging the racialised exile that is life in Canada. The Mavericks' conflicts with South Asians draw attention to what Munasinghe (2001, p. 1) describes as, the "contestation over the power to define the cultural coordinates of the symbolic space of the nation." Although Munasinghe was referring to the nation of Trinidad, it is worth thinking through how liming is essential to (re-)making Canada as well.

The Mavericks' version of the sport is impeded by the presence of South Asians (and their foods and languages) within a diaspora space. At cricket matches, the home team is always responsible for providing the food. Increasingly, when the Mavericks play with or for the police team, the chicken offered is tandoori instead of jerk. Ladoos and samosas have supplanted plantains and dumplings, and drinking is prohibited. Curry and rice may be the only staples on which South Asian and Caribbean groups can agree; however, the ways in which these dishes are prepared seem to continually keep the groups apart. These conflicts are characteristic of "diaspora spaces," where different ethnic groups find themselves together, negotiating for material and discursive power (Brah, 1996). The Mavericks are at once part of a community that is "dispersed" and "at home." Their cricket games in the Greater Toronto Area require excluding South Asian bodies in favour of competing against Afro-Caribbeans. Theirs is "a practice of dwelling (differently) ... an ambivalent refusal or indefinite deferral of return" (Clifford, 1994, p. 321). They do not need to return to their homelands to recreate homespaces and their national affiliations proliferate with each year after emigration. The grounds offer a place for solidarity both to an elsewhere and to the Canadian nation-state. The next chapter explores the various ways in which nations are differentiated and reproduced in this itinerant cricket and social club. 


\section{Notes}

1 Munasinghe (2001) remarks that during the 1980s and early 1990s, "Indo-Trinidadian cultural activists, religious and political leaders, moderates and radicals, were united in their efforts to challenge hegemonic Afro-Creole representations of the nation" (p. 7). In Trinidad as in Guyana and Surinam, Indians were relegated to a fourth tier in the social structure, behind Europeans, elite blacks and creoles, and lower-class blacks. Their social and spatial isolation during indentureship operated to situate them symbolically outside the core of society (p. 10).

2 My own positionality, as a dark-skinned black woman, and the knowledge of my research as a project on the "Black Atlantic" potentially influenced how MCSC members chose to identify themselves and others in conversations with me.

3 "Negro" " is a term used as a conscious sign of respect among older Caribbean persons (Peake and Trotz, 1999, p. 26).

4 It is notable that conservative Indo-Caribbeans fiercely resist the "cross-over" from chutney performed in Indian wedding tents "to the further hybridized chutney soca, the "Africanized" and carnivalised form of chutney performed during carnival" (Puri, 1999, p. 26), which potentially renders invisible its Indianness and publically stages the sexuality of the Indo-Caribbean woman. The point here is that by Afro- and IndoCaribbeans alike, chutney-soca is seen as a blackened art form and it should be no surprise that this is the only form of Indo-Caribbean culture welcomed by this cricket and social club.

5 The cultural specifics of Indo-Caribbean cricket experience is worthy of attention; there is something similar yet different at stake for Indo-Guyanese or Indo-Trinidadians in this Caribbean community. Their reasons for distinguishing themselves from South Asians, desire or capacity to forge alliances with South Asian or Indo-Caribbean teams, or feelings of exclusion within the MCSC deserve to be explored, but are outside the scope of this study. Sport in the Black Atlantic does not capture all the makings of Caribbean identity through cricket in the Caribbean diaspora. 